\title{
Neoplasia papilar mucinosa intraductal de páncreas
}

\section{¿QUÉ ES LA NEOPLASIA PAPILAR MUCIMOSA INTRADUCTAL ?}

La neoplasia papilar mucinosa intraductal (NPMI), es una entidad que engloba una serie de lesiones proliferativas de aspecto papilar productoras de moco y dependientes del epitelio del conducto pancreático principal (conducto de Winsung) o de alguna de sus ramas accesorias.

\section{¿CÓMO SE DIAGNOSTICA?}

El diagnóstico se realiza por la TAC abdominal y la colangio resonancia magnética nuclear. Estas exploraciones son cruciales para establecer el diagnóstico y el tipo de afectación, del conducto pancreático, aspecto que determina el tratamiento quirúrgico y el pronóstico. En ocasiones es útil la ecoendoscopia y la citología obtenida por punción. Dependiendo de la afectación del conducto pancreático; la NPMI se clasifica en:

- Afectación del conducto pancreático principal.

- Afectación de una o varias ramas accesorias del conducto principal: tipo accesorio.

- Tipo mixto cuando coinciden ambos tipos de lesiones, del conducto principal y de ramas accesorias.

\section{¿POR QUÉ SE LLAMA NEOPLASIA?}

Se denomina "neoplasia" porque en su evolución natural progresa a lesiones malignas invasivas, por lo que en la gran mayoría de los casos (los del conducto principal) el tratamiento será quirúrgico. Cerca del $40 \%$ de los pacientes intervenidos -especialmente del tipo I- presentan transformación maligna invasiva.

La secreción de moco (mucina) en el conducto pancreático da lugar a una dilatación quística; motivo por el que se incluye dentro de los tumores quísticos de páncreas, de los que la NPMI, representa el $30-35 \%$

\section{¿CÓMO SE MANIFIESTA?}

A diferencia de las otras lesiones quísticas del páncreas, la NPMI es más frecuente en varones y se suele diagnosticar entre la $6^{\mathrm{a}}$ y $7^{\mathrm{a}}$ década de la vida. La sintomatología es muy variada, ya que puede detectarse como un hallazgo casual en una exploración abdominal (ecografía, tomografía axial computarizada; TAC) o dolor abdominal, pérdida de peso, ictericia por obstrucción biliar por la producción de moco- o episodios recurrentes de pancreatitis.

\section{¿CUÁNDO EXISTE INDICACIÓN QUIRÚRGICA?}

Se debe realizar la resección pancreática en todos los casos de afectación tipo I, II y en los tipo III cuando la lesión sea $\geq 3$ $\mathrm{cm}$, presente síntomas o signos radiológicas como presencia de nódulos, edad $>70$ años y que se asocie a dilatación del conducto principal $\geq 7 \mathrm{~mm}$.

\section{¿QUÉ TIPO DE RESECCIÓN PANCREÁTICA SE DEBE REALIZAR?}

Se debe extirpar el parénquima pancreático correspondiente a la porción del conducto afectado. Dependiendo de la localización -cabeza, cuerpo y cola- se realizan duodenopancreatectomía cefálica, centrales o pancreatectomía distal.

\section{¿EN QUÉ CASOS ES POSIBLE EL SEGUIMIENTO Y OBSERVACIÓN?}

Se puede realizar seguimiento en las lesiones tipo III -únicas de rama accesoria- de un tamaño $\leq 3 \mathrm{~cm}$, asintomáticas y $\sin$ la presencia de nódulos o dilatación del conducto principal.

\section{¿CUÁL ES EL PRONÓSTICO?}

En líneas generales, con la resección curativa, y sin presencia de cáncer invasivo la supervivencia a los 5 años es superior al $70 \%$ y en algunas series supera el $90 \%$. Cuando en la pieza quirúrgica existe invasión carcinomatosa la supervivencia a los 5 años es del 30-50\%.

Javier A.-Cienfuegos y Fernando Rotellar

Departamento de Cirugía General y Digestiva. Clínica Universidad de Navarra 